\title{
Nasal secretion insufficiency syndrome (new concept of ozena)
}

\begin{abstract}
The patient complained of nasal odor and was referred to a psychiatrist by the Department of Otolaryngology as a case of olfactory reference syndrome. The patient had a strong nasal odor. The doctor denied the existence of atrophic rhinitis and rhinophobia.

If you look around the internet, there are many who suffer from similar conditions. Almost all of them complain of an unusually dry nose. It was thought that Pseudomonas aeruginosa or some fungus grew abnormally in the devastated nasal mucosa of the endogenous nasal cavity, and due to inadequate nasal secretion, the bacterial metabolites could not be forced down the throat or other parts of the body, giving off a strong nasal odor. This disorder is often neglected or diagnosed by psychiatrists as olfactory reference syndrome. The term "nasal secretion insufficiency syndrome" is used to describe this condition. This is a new concept of nasal odor disease, which remains unnoticed, partly because there is no crusting or atrophy of the native nasal cavity, and partly because endoscopy reveals only the devastation of the nasal mucosa, and partly because it is hidden behind the veil of atrophic rhinitis and ozena.
\end{abstract}

In all seven cases, the foul odor is weakened, albeit temporarily, by the use of salivaenhancing drugs.

Keywords: new concept of ozena, nasal secretion insufficiency syndrome, olfactory reference syndrome, drugs that stimulate saliva production
Volume 7 Issue 2 - 2020

Toshiro Takami

Akiyama hospital, Japan

Correspondence: Toshiro takami, Akiyama hospital, 47-8 Kuyamadai Isahaya-shi Nagasaki-prefecture, 854-0067, Japan, Tel 080-52 I I-3990, Email mmm8289@yahoo.co.jp

Received: August 22, 2020 | Published: September 18, 2020

\section{Introduction}

The odor is weaker than that of atrophic rhinitis and ozena due to the abnormal growth of some bacteria in the mucosa of the nasal cavity of the nasal cavity without forming a crust. When patients complain of nasal odor, they are not applicable to the concept of atrophic rhinitis or ozena, so most of them are referred to the psychiatry department for olfactory reference syndrome. ${ }^{1}$ The nasal secretion insufficiency syndrome is the condition of the nasal secretion insufficiency, which means that the tissue secreting nasal juice is damaged and the nasal secretion is decreased. The causes of the disease are thought to be diverse. The most common cause is the gradual or rapid damage to the nasal mucosa caused by rhinosinusitis. Other causes are more common in those working in freezers.

Although the frequency of this disorder is high, almost all have been diagnosed as olfactory reference syndrome. However, the stench can be so strong that many refuse to be in the same room. ${ }^{2}$

The number of tormentors has increased dramatically, and it is now very common for people to be tormented as "stinky" people. Many of them have become socially withdrawn or withdrawn.

Atrophic rhinitis and ozena is mentioned in ancient Egyptian documents as a mysterious disease. Atrophic rhinitis and ozena was proposed by B. Frankel to be accompanied by three main signs of "foul odor, atrophy, and crusting" and is believed to have laid the groundwork for a single disease. ${ }^{3}$

Previously, the frequency of atrophic rhinitis and ozena was high worldwide, and the etiology of the disease has been the subject of much debate. It was known empirically that the administration of female hormones was effective, that the disease often resolved spontaneously in old age, that the incidence rate in females was twice as high as that in males, and that the odor in female patients often became stronger or weaker in accordance with their menstrual cycles. It was suggested that hormones had a significant effect on ozena. There was also a strong theory of autonomic neuropathy, which suggested that a very large number of patients were nervous and that the bacterial infection was secondary to the bacterial infection.

The incidence of atrophic rhinitis and ozena has continued to decline since 1950, and nowadays, at least in developed countries, the incidence of atrophic rhinitis and ozena is almost non-existent. This author believes that this is due to the fact that high doses of female hormones have become the norm in modern livestock farming and aquaculture. In the rural areas where people cannot eat milk and meat due to modern livestock farming and aquaculture, atrophic rhinitis and ozena still occur at a relatively high rate.

There is a social networking site for people suffering from odor, with more than 200 registered users, mostly women, ranging in age from 14 to 56 years old. People who suffer from a wide range of odors such as bad breath, nasal odor, body odor, and the gas form of irritable bowel syndrome (IBS) have registered on the site. Until a few years ago, the name "Friends of the Nasal Odor Sufferers" was used because the organizer suffers from nasal odor. It is believed that many people with bad breath and body odor have nasal odor but are not aware of it.

Many of the participants in this SNS are afraid of self-odor, but some of them can only think of it as really smelly. These were thought to be inadequate nasal secretion for a variety of reasons. The cases are described below.

In all of the following seven cases, the foul odor subsided, though temporarily, when medication to promote salivation was taken. 
The reason for this is that when saliva secretion is promoted, nasal secretion is also promoted.

\section{Case}

\section{(Case I) 54-years-old, male}

Family history: father and sister and nervousness (sister and two brothers)

Personality: Stubborn, enthusiastic, picky, gentle, nervous and obsessive tendencies

Life history: Good grades since childhood (for privacy reasons)

History: At the age of 28, he developed depressive disorder, and his condition has continued to be mild and severe.

At the age of 32, he developed psychogenic pollakiuria, which has continued to this day.

Current medical history: In the winter of the first year of elementary school, he developed rhinosinusitis. Since then, he suffered greatly from nasal discharge during class. In the winter of the second year of junior high school, he noticed that the left nasal bone was swollen. Although the middle nasal cavity was forming (Figure 1) the case was left alone without concern.

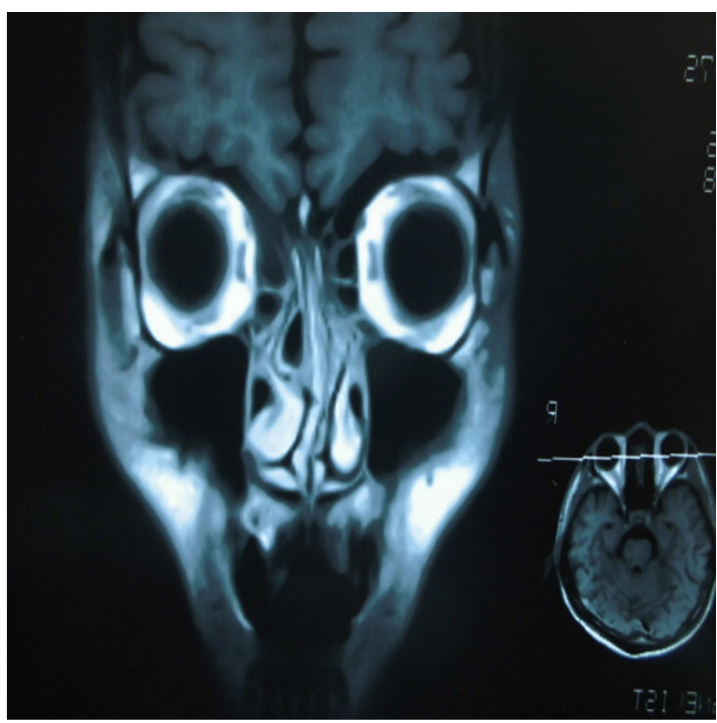

Figure I Middle turbinate honeycomb in case I.

Since the spring of his sophomore year of high school, his rhinosinusitis has become milder or his secretions have decreased, and he is no longer bothered by the nasal discharge that comes out during class.

He have been suffering from bad breath for many years since he graduated from high school. He thought his bad breath was caused by chronic gastritis.

A few years ago, he self-diagnosed that his bad breath was caused by gastroesophageal reflux disease and underwent gastrointestinal contrast and 24-hour esophageal $\mathrm{pH}$ monitoring at a university hospital.

After 24-hour gastroesophageal $\mathrm{pH}$ monitoring, he began to think that his odor was nasal odor and not halitosis. It was around the time when he was agonizing over how to cure his nasal odor, when he read about the "Association of Friends Suffering from Nasal Odor" on the Internet. In the spring of his sophomore year of high school, he went to see a famous elderly ENT doctor at the urging of his parents and was diagnosed with atrophic rhinitis (no CT or endoscope was used). However, atrophic rhinitis was ruled out by MRI as there was no atrophy of the nasal gland.

In the spring of his sophomore year of high school, his severe acne, which had plagued him since sixth grade, went into dramatic remission. This coincided exactly with the period when he no longer struggled with the nasal discharge that came up during class. The case believes that around this time, due to her sister's severe acne, her diet changed to emphasize vegetables, and this altered her gut microbiota, which in turn altered the flora of her skin and intrinsic nasal cavity.

He believed that he had a strong nasal odor from his sophomore year of high school, or at least the winter of his junior year of high school, when he stopped struggling in class because of his nasal discharge, if memory serves (I remember avoiding it while studying in the library in the winter of my junior year of high school).

Further traversing the memory, the nasal odor started in my junior year of middle school when he started eating a lot of meat. he began to think that the meat was covered in antibiotics and that this killed off Staphylococcus lugdunensis in the endemic nasal cavity, allowing Staphylococcus aureus to grow abnormally in the endemic nasal cavity. ${ }^{4,5}$

He imported mupirocin, which is widely used in surgery to selectively kill cocci such as Staphylococcus aureus, and used it privately, but the dryness of the intrinsic nasal cavity did not diminish (the smell was unknown).

When he noticed nasal odor, he injected lactobacillus solution into her nasal cavity, but he found out that it was effective for about one hour, so he now inhales horse oil in his nasal cavity. However, he found that the effect was about one hour, so he now use horse oil for intranasal inhalation, which is not as strong a cleansing agent, but the effect lasts a long time. He also reads books on horse oil and inhales horse oil into the nasal cavity in the hope that the oil will regenerate the devastated nasal mucosa.

He always wears a mask to reduce the thirst of his nasal passages, but his nasal passages feel very dry, and only a little watery nasal secretions are occasionally emitted. When he touches the nasal mucosa of his nasal cavity with a cotton swab, he can see that it is rough.

He was referred to a psychiatrist because he thought he had fungal rhinosinusitis and was diagnosed as having fungal rhinosinusitis. There is no internal disease. There is no known reaction of the surroundings, i.e., coughing and sniffing.

(Case 2 and below are six cases of "Nasal Secretion Deficiency Syndrome" probable. $)^{6}$

\section{(Case 2) 3 I-years-old, male}

Current medical history: He claims to have developed odorophobia naturally since he began working in a freezer at age 19 .

1. He visited an ENT, but was diagnosed with auto-odorophobia. No history of psychiatric consultations.

2. He works diligently at his job without a break. He still works in the freezer most of the time. He rarely has close contact with people at work. He has never been bullied. 
3. He can't let people ride in his car because he think it smells bad, and when he go to people's houses to play, he always wash his nasal passages in the car with a device that washes them with saline solution or something else before he go into people's houses.

4. If he doesn't wear a mask to bed on a tired day, he gets nosebleeds when he wakes up because it's too dry.

5. He has a serious and honest personality. He always wears a mask, but he only occasionally has a small amount of watery nasal discharge that is not viscous. No nasal hair. There is no internal disease. There is no known reaction of the surroundings, i.e., coughing and sniffing.

\section{(Case 3) 37-years-old, male}

Current medical history: When he was in high school, he visited several ENT clinics because he claimed that during the winter he fell asleep in front of a hot air heater and inhaled hot air for a long time, which caused pressure ulcers to form in his native nasal cavity and emitted nasal odor. One of the ENT departments diagnosed him with olfactory reference syndrome and recommended that he see a psychosomatic physician, who referred him to a psychosomatic physician and he continues to see a psychosomatic physician. He still goes to a psychosomatic physician because he needs sleeping pills. ${ }^{7,8}$

He works at the Y Department and has never been tormented. This is presumably due to the fact that his case work at the Y Department involves very little close contact with people; he works in a department at the Y Department that has a very high number of night shifts; when he joined the Y Department, he was concerned about nasal odor, so he chose his current department, which most people avoid.

He wrote: "Dry winter is the problem, the smell gets worse when it's dry" and "I've been applying Vaseline and wearing masks lately to prevent dryness.

His personality is serious and straightforward. He always wears a mask, but only occasionally has a small amount of watery nasal discharge. He has no medical problems. There is no known reaction to his surroundings, i.e. coughing and sniffling.

\section{(Case 4) 56-years-old, male}

Current medical history: He had bad ears and nose since the early years of elementary school and had to go to an ENT clinic. When he was in junior high school and high school, he had a hard time in class because he had a lot of nasal discharge.

After graduating from high school, he joined the Tokyo branch of Company A. He worked on the floor with nearly 200 people. There, he is accused of "smelling" by the company's employees. However, he didn't pay much attention to it.

When he was 30 years old, he was transferred to the Osaka branch. Here too, he works on the floor with nearly 200 people. Rumors of his time in the Tokyo branch have spread, and the same employees have been talking behind his back about the "smell" of the office. It happened frequently that younger employees would come near the cases and smell them and say they "stunk". The case was distressed and underwent surgery for rhinosinusitis at a university hospital. It is presumed that this kind of torment could have happened because the workplace had a lot of time on his hands.
He found a website called "The Association of Friends Suffering from Nasal Odor," where he thought he was suffering from rhinosinusitis. He wrote: "I have been told by an ENT specialist that there was no crusting or atrophy of the nasal cavity, but it could be atrophic rhinitis and that the mucous membrane was severely damaged.

One ENT clinic wrote a referral to a psychiatrist and he have seen a psychiatrist. The psychiatrist diagnosed him with a fear of selfodorization and prescribed alprazolam and sulpiride. His personality is amicable and highly social. He has three children and his family is happy. He has no medical problems. There are no known reactions, i.e. coughing and sniffing. ${ }^{9,10}$

\section{(Case 5) 29-years-old, female}

Current medical history: She had been treated by an ENT clinic for rhinosinusitis since her early elementary school years. She has been taking antibiotics since her early elementary school days. It seems that she has been giving off a bad smell since her junior high school days, but it's not clear, maybe she has been giving off a bad smell since her elementary school days.

The self-introduction on the "odor trouble social network" reads as follows

"I haven't laughed from my heart in years.

She have learned to laugh with her mouth closed because when she laugh, she give off a smell.

She have learned to keep conversations short and to use words as much as possible.

She make an effort to breathe in as much as she can on her own.

The people around her don't know about this effort.

And that's why they offer her breath care. They offers me a Fabreeze.

They are doing this out of kindness, and that action makes her suffer even more.

She love kids, and She want to be married.

But she have been shutting everything down because she feel like she should not be in a relationship because of this smell.

"I'm all about work. LOL.

I'm in the customer service industry, ready to be a nuisance.

The smelly, dark, and unworkable ones, than the ones who can't work.

I want a stinky, but energetic, workmanlike guy.

I think it's only recently that I've started to go for it.

I've been to a famous dentist. I had a physical exam. I even took a gastroscope. I've even tried herbal medicine. And yet, I couldn't figure out where or what was giving off this smell. It was six months ago that I realized it was nasal odor.

When will I ever be able to truly laugh?"

She claims that her nasal odor often becomes stronger and nasal odor almost disappears in response to her menstrual cycle. 
"A couple of ENTs told me that the mucous membranes in my nose were very rough," he says, "I could barely smell it, and the ENT said, The nerve cells in my sense of smell have been abolished. Why did you let it go? In summer I smelled rotten fish, and in autumn and winter I smelled a fart. His character is serious and straightforward. Watery nasal discharge is occasionally slight. There is no internal disease. She is hypersensitive to the reactions of her surroundings, such as coughing and sniffing.

\section{(Case 6) 48-years-old, female}

Current medical history: In the fourth grade of elementary school, he developed rhinosinusitis. After entering junior high school, he had frequent nasal congestion and difficulty breathing through his nose at night. At the same time, she found out that her nose was emitting a foul smell. She went to the ear, nose and throat clinic to complain about her nasal odor, but she was lightly treated. Around this time, her classmates called her "stinky" and tormented her severely by the female guard. In the second year of junior high school, she started taking an over-the-counter Chinese herbal medicine for rhinosinusitis and ozena, which was said to be effective. After researching in the library, she realized that her condition was probably due to her own odorous nose disorder. When she was in junior high school, she was told that she smelled "fart smell" and "feces smell".

When she was in her twenties, she went to an ENT clinic and was told that "the inside of her nose is completely black! She must be puking on a cigarette like Godzilla! (Case does not smoke.) At that time, her rhinosinusitis was so bad that she was emitting a lot of green nasal discharge, and she was fussed over at work, pointing to the place where the patient was, saying, "That area smells squidgy and fishy!" This was right after taking antibiotics for seven days, and it is assumed that Pseudomonas aeruginosa had been growing abnormally.

She had seen many ENT doctors, but one ENT told her that she had "weak atrophy of the nasal cavity, not atrophic rhinitis, but weak atrophy of the nasal cavity, with very rough nasal mucosa.

She imported Mupirocin privately and used it, but stopped using it after a few days when it came to her stomach (stomach upset) and she didn't feel any effect.

She claims that her nasal odor becomes stronger or weaker depending on her menstrual cycle, especially during menstruation (she can't smell it herself, so she judges it from the reactions of others).

She writes: "After taking the medicine (note: etizolam), the reactions of people around me, such as coughing and sniffing, disappear completely," "My son also has nasal odor," and "When she catches a cold and has a runny nose, the odor gets weaker"; "I used to import etizolam from the Internet.

Recently, she said, she has been receiving many complaints about the "smell of farts" and "feces." She is severely concerned about people with strong breath odor at work and elsewhere. She is extremely sensitive to odors. At home, she makes her children check the smell, and when he say, "I don't have a smell," she criticizes him, telling him to tell the truth, until he cry.

"When the smell is bad, there's no pus or nasal discharge (my nose gets dry).

When the smell is lessened, it feels like pus is coming out and my nose is moist.
The point is, as long as you're able to excrete the pus, the smell isn't too bad.

If excretion is blocked and pus builds up in the maxillary sinuses, etc., a foul odor will ensue! This is the kind of scheme I'm thinking of."

She writes. "I severely dislike being called "olfactory reference syndrome" and "overly concerned". She don't have an internal disease. She is extremely sensitive to the reactions of her surroundings, i.e. coughing and sniffing.

\section{(Case 7) 28-years-old, female}

Current medical history: She is not sure when she started to smell bad. At least when she started working, she began to have a nasal odor.

When she goes to work, she inhales horse oil in her nasal passages at home, which is not stinky in the morning, but in the afternoon she emits a foul odor, which is annoying to the people around her and disliked by the people around her as "smelly". The fact that horse oil reduces nasal odor is a fact she learned about and practiced in "Friends of Nose Odor".

She says that nasal rinsing with saline solution is only effective for about two hours.

She avoids romance because she thinks she's stinky.

Her personality is honest and serious. She is also thought to have a mixture of nasal secretion insufficiency syndrome and olfactory reference syndrome.

**Thus, from the above seven cases, men seem to be insensitive to surrounding reactions, that is, coughing and sniffing, but many men are hypersensitive to surrounding reactions and at least concurrent olfactory reference syndrome in this SNS. **All three of the women listed above concurrent olfactory reference syndrome.

\section{Discussion}

It is not clear what fungus destroys the native nasal mucosa, which contains nasal glands and goblet cells that produce nasal secretions.

Many nasal odor sufferers claim that taking common antibiotics will dramatically reduce the odor for a few days.

Many nasal odor sufferers complain of slight nasal discharge and a strong dry feeling. This may be due to the strong irritation of the nasal mucosa.

It is believed that nasal odor becomes stronger in response to the menstrual cycle and that nasal odor becomes stronger during menstruation. This is because the microbiota in the nasal cavity changes in response to the menstrual cycle. This is consistent with the ancient theory that hormones are the etiology of atrophic rhinitis and rhinorrhea, and that the odor of atrophic rhinitis and rhinorrhea increases during menstruation. Several women who participated in this "odor worries social networking service" did not recognize the odor themselves, so they guessed it based on the reactions of their neighbors, but their sensitivity to the reactions of their neighbors was extremely high, so we believe they were correct in their judgment.

Even if the nasal cavity is rinsed with saline at night, the next morning the nasal cavity still emits a foul odor. Nasal rinsing with saline may be effective for a short time, but the effect is not long, often lasting up to 2 hours. 
There are a large number of people on this social networking site(SNS) who claim that taking benzodiazepines dramatically eliminates the reactions around them, i.e. coughing and sniffling. However, nasal secretion is controlled by the parasympathetic nervous system, and taking benzodiazepines may relieve sympathetic nervous system overstimulation, so that parasympathetic nervous system activity is no longer inhibited and nasal secretion is promoted, which may lead to a weakening of nasal odor. ${ }^{11-15}$

\section{Finally}

This new condition was present in large numbers before 1955 when atrophic rhinitis and ozena were common, because rhinosinusitis was very common. It is also possible that the patient may have been diagnosed with a mild form of atrophic rhinitis/ozena.

At least in nasal odor, it is likely that many of them are misdiagnosed as having a real odor, at least in terms of nasal odor, but with olfactory reference syndrome. Many patients with nasal odor complain of nasal odor are rinsing their nasal passages with saline solution several times a day and the odor is weak. Many patients complain of nasal odor only in autumn and winter when the air is dry.

Some of the patients who complain of nasal odor and have olfactory reference syndrome may have nasal insufficiency syndrome. It is difficult to recognize nasal odor by oneself, so the patients who complain of halitosis and body odor may have the nasal secretion insufficiency syndrome.

\section{Conflicts of interest}

The authors declare that they have no conflict of interests.

\section{References}

1. Begum M, McKenna PJ. Olfactory reference syndrome: A systematic review of the world literature. Psychol Med. 2011;41(3):453-461.

2. Brook I, Yocum P, Shah K. Aerobic and anaerobic bacteriology of concurrent chronic otitis media with effusion and chronic sinusitis in children. Arch Otolargyngol Head Neck Surg. 2000;126(2):174-176.
3. Bunnag C, Jareoncharsri P, Tansuriyawong P. Characteristics of atrophic rhinitis in Thai patients at the Siriraj Hospital. Rhinology. 1999;37(3):125130 .

4. Effat KG, Madany NM. Microbiological study of role of fungi in primary atrophic rhinitis. J Laryngol Otol. 2009;123(6):631-634.

5. Konvalinka A, Errett L, Fong IW. Impact of treating Staphylococcus aureus nasal carriers on wound infections in cardiac surgery. $J$ Hosp Infect. 2006;64(2):162-168.

6. Mainak D, Soumya G. Acute Exacerbation of Chronic Rhinosinusitis (AECRS) with Orbital Complications in an Atrophic Rhinitis Patient: A Mere Co-incidence? J Clin Diagn Res Dec. 2013;7(12):2973-2975.

7. Orlandi RR, Kingdom TT, Hwang PH, et al. International consensus statement on allergy and rhinology: rhinosinusitis. Int Forum Allergy Rhinol. 2016;6Supp11:S22-S209.

8. Phillips KA, McElroy SL, Keck PE, et al. A comparison of delusional and nondelusional body dysmorphic disorder in 100 cases. Psychopharmacol Bull. 1994;30:179-186.

9. Ralph M, Kija SH, Hans-Peter H. Dexpanthenol: an overview of its contribution to symptom relief in acute rhinitis treated with decongestant nasal sprays. Adv Ther. 2017;34(8):1850-1858.

10. Dutt SN, Kameswaran M. The aetiology and management of atrophic rhinitis. J Laryngol Otol. 2005;119(11):843-852.

11. Wald ER. Staphylococcus aureus: is it a pathogen of acute bacterial sinusitis in children and adults? Clin Infect Dis. 2012;54:826-831.

12. Wong J, Kwon $\mathrm{H}$, Jang Y. Rhinovirus enhances various bacterial adhesions to nasal epithelial cells simultaneously. Laryngoscope. 2009;119(7):1406-1411.

13. Yang J, Zhang Q. Twenty three cases of atrophic rhinitis treated by deep puncture at three points in the nasal region. $J$ Tradit Chin Med. 1999;19(2):115-117.

14. Zipperer A, Konnerth MC, Martin C. Human commensals producing a novel antibiotic impair pathogen colonization. Nature. 2016; 535(7613):511-516.

15. Zohar Y, Talmi YP, Strauss M, et al. Ozena revisited. J Otolaryngol. 1990;19(5):345-349. 